\title{
Physical Activity of Preschool Children in COVID-19 Pandemic: Focusing on Activity Content and Exercise Intensity during Childcare
}

\author{
Mao Hashimoto1 ${ }^{*}$, Takayuki Shishido ${ }^{2}$, Satoru Kowa ${ }^{1}$ \\ ${ }^{1}$ Division of Art, Music, and Physical Education, Osaka Kyoiku University, Osaka, Japan \\ ${ }^{2}$ Department of Human Science, Tohoku Gakuin University, Miyagi, Japan \\ Email: ^hashimoto-m82@cc.osaka-kyoiku.ac.jp
}

How to cite this paper: Hashimoto, M., Shishido, T., \& Kowa, S. (2021). Physical Activity of Preschool Children in COVID-19 Pandemic: Focusing on Activity Content and Exercise Intensity during Childcare. Creative Education, 12, 999-1010. https://doi.org/10.4236/ce.2021.125073

Received: April 2, 2021

Accepted: May 21, 2021

Published: May 24, 2021

Copyright $\odot 2021$ by author(s) and Scientific Research Publishing Inc. This work is licensed under the Creative Commons Attribution International License (CC BY 4.0).

http://creativecommons.org/licenses/by/4.0/

(c) (i) Open Access

\begin{abstract}
The present study examined the relationship between children's activities at a nursery school and the amount of physical activity in the COVID-19 pandemic and obtained primary data to promote future childcare activities. Healthy preschool children aged $3-5(\mathrm{~N}=21)$ participated in the survey. Children wore an activity tracker (Polar, A360) on the wrist of the non-dominant hand for three hours in the morning on five days, just after the state of emergency was lifted. The measurements included "activity time", "moderate-to-vigorous physical activity (MVPA) time", and "average heart rate (HR)". The activity time was defined as physical activity time with an intensity of over $60 \% \mathrm{HRmax}$ (maximum heart rate). MVPA time was defined as time doing physical activity with an intensity higher than 70\% HRmax. From the results of this study, in childcare under COVID-19 pandemic, the activity time of each day was 37.8 $\pm 25.0 \mathrm{~min}$ to $87.0 \pm 34.7 \mathrm{~min}$, and the MVPA time was $4.7 \pm 6.3 \mathrm{~min}$ to 33.7 $\pm 26.1 \mathrm{~min}$, and the average heart rate was $111.3 \pm 7.3 \mathrm{bpm}$ at the lowest and $126.8 \pm 9.9 \mathrm{bpm}$ at the highest. In particular, the time of MVPA, which is expected to improve physical strength, was approximately $15 \mathrm{~min}$ on a five-day average, which was significantly shorter than previous studies. Children's health and development of athletic ability are hindered by insufficient opportunities for physical activities and exercise because of the current COVID-19 pandemic. Securing exercise time and increasing exercise intensity should be considered in childcare to increase children's physical activity in childcare.
\end{abstract}

\section{Keywords}

Childcare, Activity Time, Moderate-to-Vigorous Physical Activity (MVPA)

Time, Heart Rate, COVID-19 Pandemic 


\section{Introduction}

International organizations, including the WHO, recommends "MVPA for a total of 60 minutes a day" for the healthy mental and physical development of children, which is adopted by many countries (WHO, 2010; Department of Health and Ageing, 2011; NASPE, 2009; Strong et al., 2005). Furthermore, the Ministry of Education, Culture, Sports, Science, and Technology (MEXT) recommends in the "Early Childhood Exercise Guidelines" that preschool children should do physical activity for at least 60 minutes a day, mainly play activities. The time for physical activities includes playing indoors and outdoors and daily life activities because although playing outdoors is desirable for preschool children, it is not always possible due to factors such as the environment, weather, and the season (MEXT, 2012).

On the other hand, Fisher indicated that fundamental movement skills were associated with young children's habitual, moderate-to-vigorous physical activities (Fisher, 2005). Moreover, Williams reported that high-intensity physical activities were correlated with young children's fundamental movement skills (Williams et al., 2008). We should ensure preschool children's opportunities to participate in physical activities to maintain their lifelong health and improve their physical strength and athletic ability.

However, in 2020, children's physical activity environment changed dramatically because of the spread of COVID-19 infection. The Japanese government declared a state of emergency and requested people to restrict their activities, including refraining from nonessential and non-urgent outgoings. A survey of preschool children's activities during the state of emergency reported a decrease in the number of footsteps taken by both children and their parents; and a 20\% $60 \%$ decrease of footsteps in children aged 3 - 5 (Naito et al., 2020).

Because of the above conditions, parents and nursery teachers have become concerned about children's mental and physical health and the degree of physical activity. Moreover, various considerations are required to prevent infections, such as limiting the number of participants in activities, which confuses childcare providers. Therefore, nursery teachers are seeking new childcare methods for the so-called New Normal.

However, no survey data have provided functional criteria for childcare activities after lifting the state of emergency. The present study examined relationship between children's nursery school activities and the degree of physical activities during the COVID-19 pandemic to obtain primary data for promoting future childcare activities.

\section{Methods}

\subsection{Participants}

Healthy preschool children without neurological or orthopedic illnesses aged 3 5 ( $\mathrm{N}=34 ; 17$ girls and 17 boys) participated in the survey. We obtained the written consent of the parents after explaining the purpose of the study to the 
children, their parents, and nursery teachers, and providing written explanations to parents about the purpose and significance of the assessments, protection of personal information, advantages and disadvantages of taking part in the survey, invasion, and safety management, and data publication.

Among 34 participants, we analyzed the data of 21 children that were not absent from the nursery during the assessment period. We classified the 21 children into three classes based on age; A: born in April 2016-March 2017, B: born in April 2015-March 2016, and C: born in April 2014-March 2015. (The Japanese school year begins in April and ends in March). See Table 1. The children's height and weight were measured within a precision of $0.1 \mathrm{~cm}$ and $0.1 \mathrm{~g}$, respectively. We calculated BMI based on the obtained values.

\subsection{Childcare Situation during the COVID-19 Pandemic}

Nursery teachers now regard playing outside without close contact between children as essential. The children usually use the nursery school playground with play equipment and five parks near the nursery school to which they go on foot. However, disinfection activities in four of the parks with play equipment were unsatisfactory. Therefore, children used only one park that did not have any equipment. Moreover, the teachers divided children into an exercise group in which all the children usually participated in two indoor exercise sessions to decrease the number of participants in each session. In the new arrangement, one group waited doing other things, such as reading picture books, while the other group exercised. The exercise was mainly conducted individually to avoid contact between children. Disinfecting equipment, and frequent hand-washing, among others, was conducted before and after each activity to prevent infection. Furthermore, habits such as using hand towels were changed to using disposable paper towels, which increased teachers' burden and affected the children's physical activities.

\subsection{Assessment of Physical Activity}

Children wore an activity tracker (Polar, A360, Finland, from now on referred to as WD) on the wrist of the non-dominant hand for three hours in the morning (from arriving at the nursery school to starting preparation for lunch) on five days from June 15 (Monday) to 19 (Friday), 2020, just after the state of emergency was lifted (Figure 1). Anthropometry measurements were conducted a

Table 1. Characteristics of participants.

\begin{tabular}{cccccc}
\hline Class & $\mathrm{n}$ & Age $(\mathrm{yrs})$ & Height $(\mathrm{cm})$ & Weight $(\mathrm{kg})$ & BMI $\left(\mathrm{kg} / \mathrm{m}^{2}\right)$ \\
\hline A class & 10 & $3.1 \pm 0.3$ & $98.0 \pm 4.6$ & $14.9 \pm 1.7$ & $15.5 \pm 0.9$ \\
B class & 7 & $4.3 \pm 0.5$ & $104.0 \pm 3.3$ & $16.5 \pm 1.4$ & $15.3 \pm 0.9$ \\
C class & 4 & $5.0 \pm 0.0$ & $110.6 \pm 3.4$ & $19.9 \pm 2.0$ & $16.2 \pm 0.9$ \\
All & 21 & $3.9 \pm 0.9$ & $102.4 \pm 6.2$ & $16.4 \pm 2.5$ & $15.6 \pm 0.9$ \\
\hline
\end{tabular}

(Mean $\pm \mathrm{SD})$. 


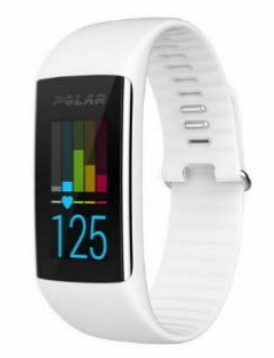

Figure 1. Wearable activity tracker (Polar A360).

week before the survey, and individual information, including the birthday, gender, height, and weight, were inputted into the WD. The measurements included "activity time", "MVPA time", and "average heart rate." The activity time was defined as physical activity time with an intensity of over $60 \%$ HRmax (maximum heart rate). MVPA time was defined as time doing physical activity with an intensity higher than $70 \%$ HRmax.

\subsection{Comparisons}

All the obtained data are indicated as mean $\pm \mathrm{SD}$. A one-way, repeated-measures analysis of variance (ANOVA) was used to compare activity time, MVPA time, and average heart rate between days. Physical activity between classes was compared using a two-way ANOVA, with the class as a between-subjects and the day as a within-subject factor. We conducted post hoc analyses of significant interactions using the SPSS Statistics version. 27 (IBM). The significance levels were set as less than $5 \%$. We checked gender differences in height and weight using unpaired t-tests, which identified no significant differences. Therefore, we did not consider gender differences in the subsequent analyses.

\section{Results}

\subsection{Content of Activity}

Table 2 shows the main content of the activity in each class on each day. Every class played outside in the park on Monday. Only B class played outdoors, and the other two classes played indoors on Tuesday. On Wednesday, every class played outside in the nursery school playground or the park, and only Class A performed gymnastics. On Thursday, all three classes played inside, including exercising for 30 minutes under an expert instructors' guidance. All three classes played indoors on Friday.

The types of play for each activity were as follows.

[Outdoor play (in the park)] Tree climbing, rock climbing, chasing each other, chasing butterflies, playing tag, racing, playing with a ball, imitative fishing, collecting stones, observing insects or fish, looking for branches, and collecting flowers.

[Outdoor play (playground)] Swings, complex play equipment, horizontal bars, teacups, playing with balls, chasing each other, play vehicles, tricycles, 
Table 2. Main activities.

\begin{tabular}{cccccc}
\hline & \multicolumn{4}{c}{ Day of the week } & \\
\cline { 2 - 6 } Class & Mon. & Tue. & Wed. & Thu. & Fri. \\
\cline { 2 - 6 } & Sunny & Sunny & Sunny & Rain & Rain \\
\cline { 2 - 6 } A class & Outdoor play (at park) & Indoor play & Outdoor play (playground+ at park), & Exercise play (indoor) & Indoor play \\
B class & Outdoor play (at park) & Outdoor play (at park) & Outdoor play (playground + at park) & Exercise play (indoor) & Indoor play \\
C class & Outdoor play (at park) & Indoor play & Outdoor play (playground) & Exercise play (indoor) & Indoor play \\
\hline
\end{tabular}

two-wheeled vehicles, hula hoop, playing with sand, drawing on the ground, playing with animals, looking for woodlice, collecting stones.

[Exercise play] A class: warm-up, jumping, walking around a mat, jumping from a vaulting box, hanging from a bar; B class: warm-up, V-shaped balance, running, one-leg balance, jumping with both legs, running and jumping, horizontal bars, vaulting box, mat exercises (forward roll); C class: warm-up, rotation jumping, walking around a mat, skipping, running, bear walking, stretching, telephoning, rolling around by putting the legs on the ears, jumping using only the hands, mat exercises (handstand), vaulting box, horizontal bars.

[Indoor play] Production play, free play (imitation play, blocks, puzzles, and drawing, among others).

\subsection{Activity Time}

Activity time with exercise intensity of higher than $60 \%$ HRmax on each day: Monday: $87.0 \pm 34.7 \mathrm{~min}$, Tuesday: $61.6 \pm 38.5 \mathrm{~min}$, Wednesday: $81.8 \pm 37.1$ min, Thursday: $73.0 \pm 35.2 \mathrm{~min}$, and Friday: $37.8 \pm 25.0 \mathrm{~min}$ (Figure 2). The results of ANOVA indicated that the difference in time depending on the day was significant $(F(4,80)=10.851, p<0.001)$. Multiple comparisons suggested that Friday's activity time was significantly shorter than Monday, Wednesday, and Thursday $(p<0.01)$.

Activity time with the optimal exercise intensity (MVPA) on each day: Monday: $33.7 \pm 26.1 \mathrm{~min}$, Tuesday: $9.8 \pm 10.1 \mathrm{~min}$, Wednesday: $23.6 \pm 25.1 \mathrm{~min}$, Thursday: $11.4 \pm 9.6 \mathrm{~min}$, and Friday: $4.7 \pm 6.3 \mathrm{~min}$ (Figure 3). The results of an ANOVA indicated that the difference in time depending on the day was significant $(\mathrm{F}(2.077,41.541)=10.964, p<0.001)$. Multiple comparisons indicated that the activity time on Monday was significantly longer than Tuesday, Thursday, and Friday and that on Wednesday and Thursday was significantly longer than Friday $(p<0.05)$.

Significant differences in the activity time among classes were not shown for either exercise intensity.

\subsection{Physical Activity}

The average heart rate on each day: Monday: $126.8 \pm 9.9 \mathrm{bpm}$, Tuesday: $117.6 \pm$ $8.7 \mathrm{bpm}$, Wednesday: $125.0 \pm 8.5 \mathrm{bpm}$, Thursday: $117.3 \pm 6.1 \mathrm{bpm}$, and Friday: 


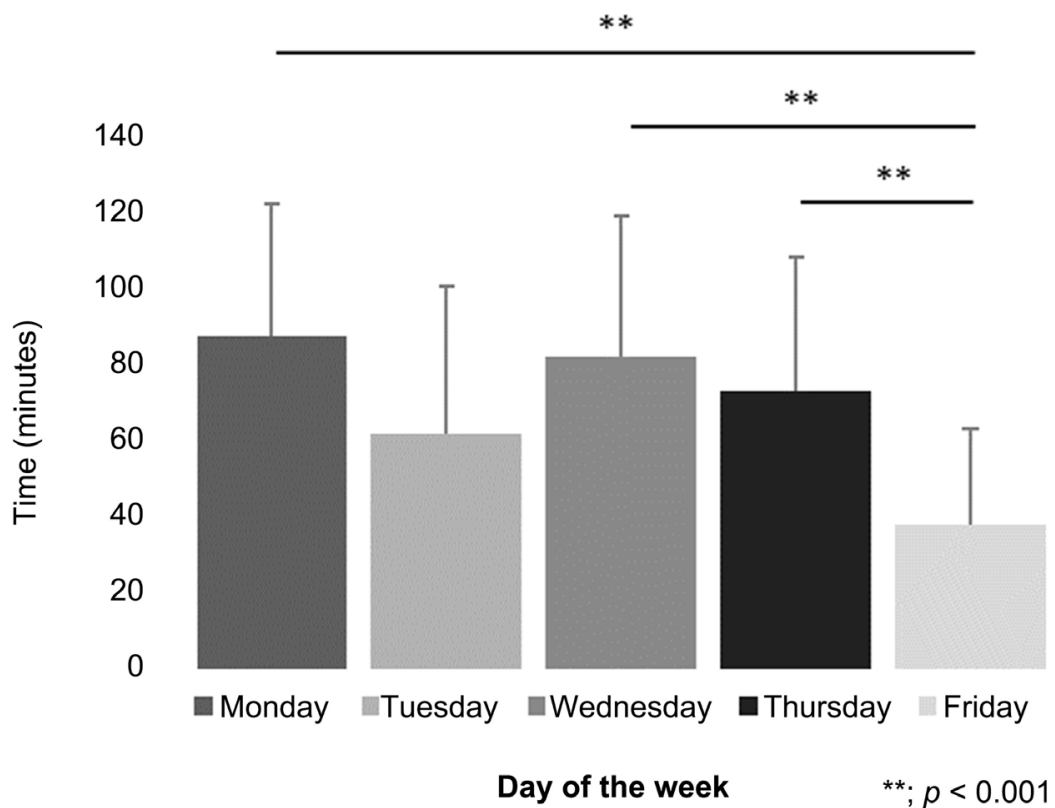

Figure 2. Activity time (60\% HRmax or more) by day of the week.

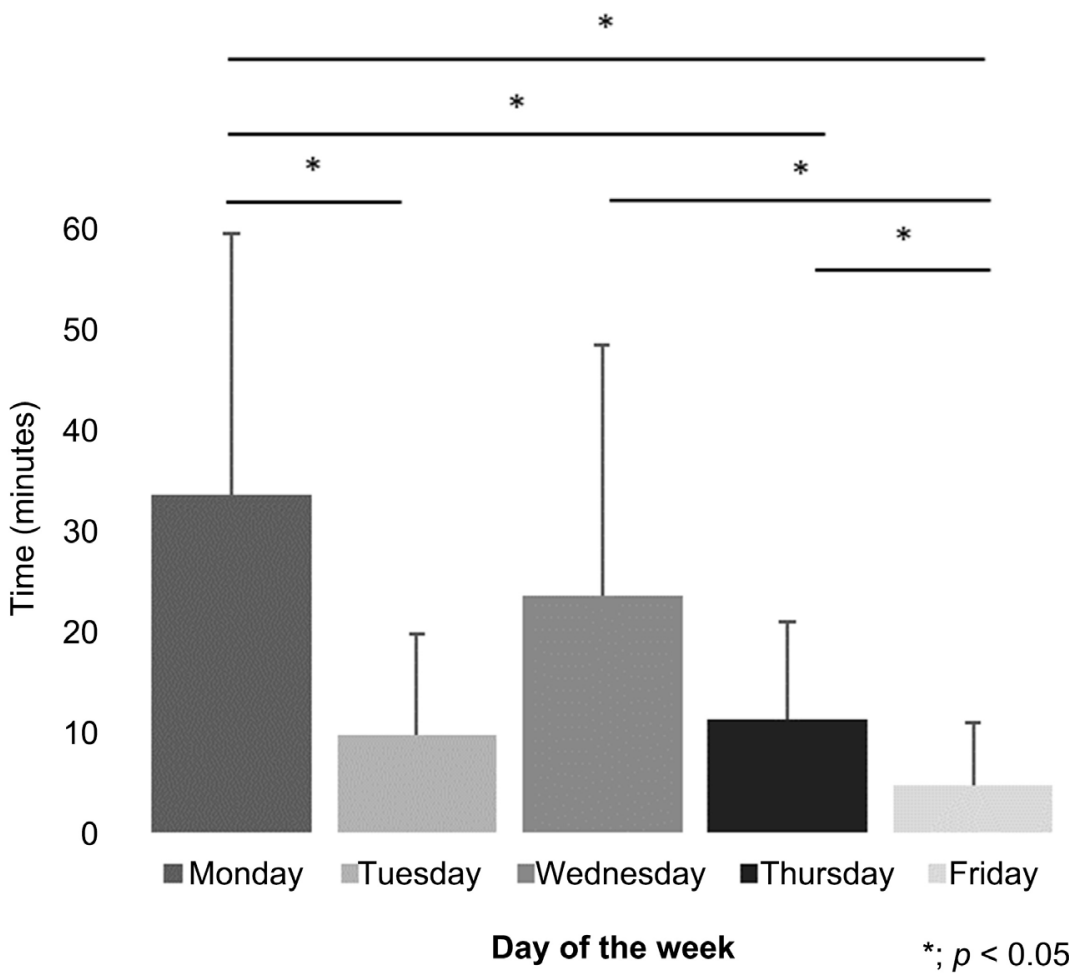

Figure 3. Activity time at optimal exercise intensity (70\% HRmax or more).

$111.3 \pm 7.3 \mathrm{bpm}$ (see Figure 4). An ANOVA results indicated that the difference depending on the day was significant $(\mathrm{F}(2.610,52.195)=20.572, p<0.001)$. Multiple comparisons indicated that the average heart rate on Monday and Wednesday was significantly higher than Tuesday, Thursday, or Friday $(p<$ 0.05). 


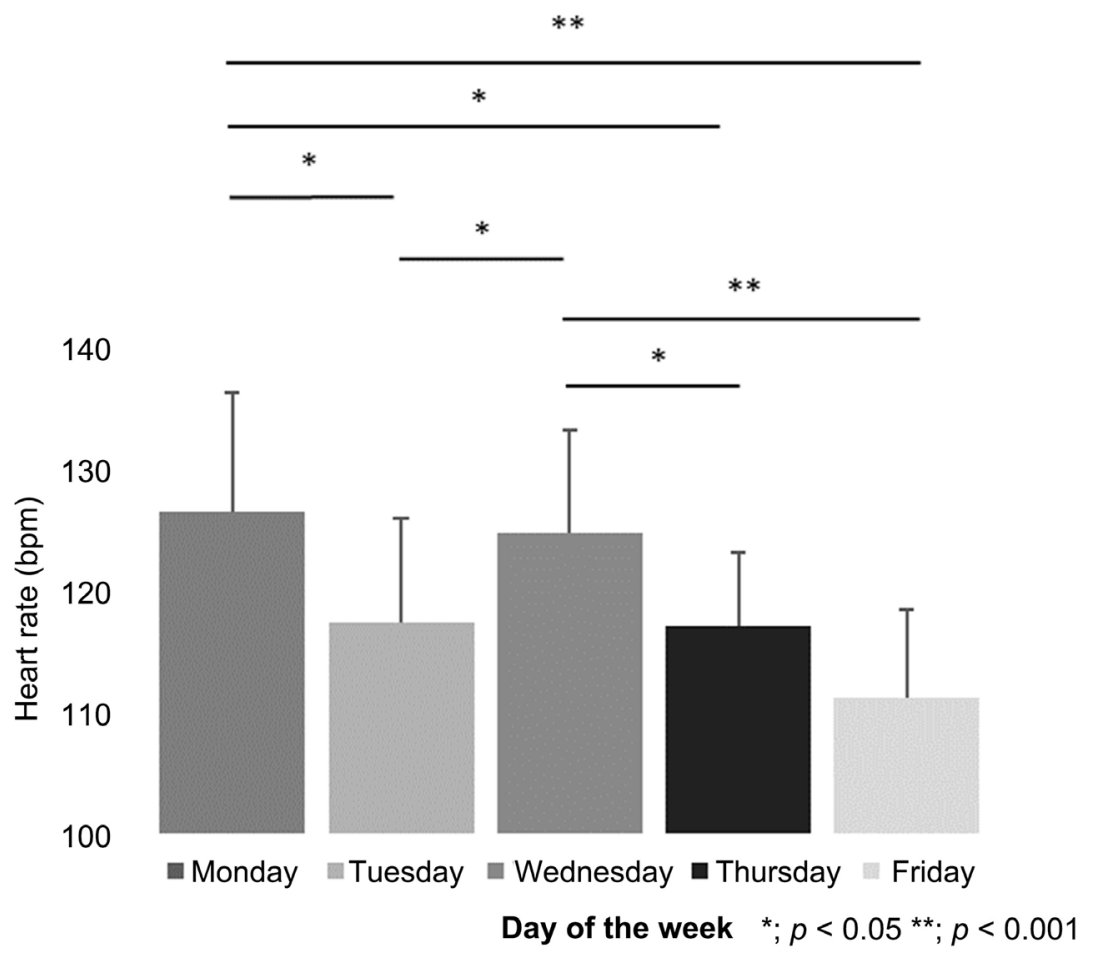

Figure 4. Mean heart rate by day of the week.

We compared the degree of physical activity among classes using a two-way ANOVA with the class as a between-subjects factor and the day as a within-subject factor, which indicated interactions between the class and day $(\mathrm{F}(8$, $72)=4.942, p<0.001)$. The results of post hoc tests indicated a significant difference between Class B and A as well as Class C on Monday $(p<0.05)$ and between Class A and B on Thursday $(p<0.05)$. In contrast, there were no significant differences on Tuesday, Wednesday, or Friday (see Figure 5).

\section{Discussion}

This study examined the relationship between preschool children's activities in a nursery school and the degree of physical activity in the COVID-19 pandemic as primary data for promoting future childcare activities. The results indicated that the time and amount of physical activity differed depending on the content of childcare.

Activity time with the exercise intensity higher than $60 \%$ HRmax on Monday, Wednesday, and Thursday was significantly longer than Friday in every class by over 60 minutes during the measurement time. On Monday, Wednesday, and Thursday, children played outside, did gymnastics, or did indoor exercise. On the other hand, children played inside on Friday because of rain, leading to a shorter activity time (37 minutes) with an intensity higher than 60\% HRmax. Although it also rained on Thursday, children conducted exercise play under instructors' guidance, leading to a significantly longer activity time than on Friday. It was sunny on Tuesday, but only Class B played outdoors, and Classes A and C 


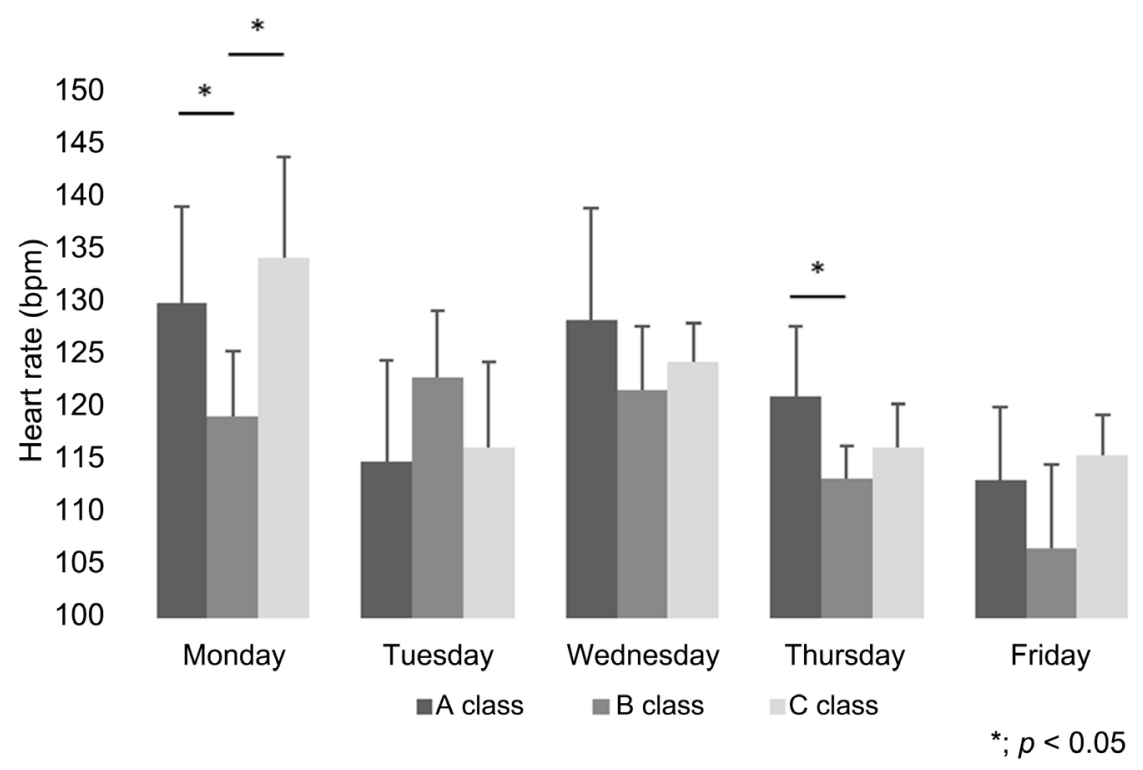

Figure 5. Mean heart rate by grade.

played indoors, which was not significantly different from Friday. Children's physical activity time is considered to be affected by the childcare content. The above results support Kinoshita's study's contention that childcare content affects preschool children's development (Kinosita, 2017).

The time of MVPA (higher than 70\% HRmax) was $33.7 \pm 26.1 \mathrm{~min}$ at maximum on Monday and $4.7 \pm 6.3 \mathrm{~min}$ at a minimum on Friday, approximately 15 min on a five-day average, which was significantly shorter than in the study by Tanaka on Japanese preschool children's daily MVPA time; $111 \pm 31 \mathrm{~min}$ in boys and $91 \pm 26 \mathrm{~min}$ in girls (Tanaka, 2015). Akitake reported that 4 -year-old children had an activity time of $61.0 \pm 15.7 \mathrm{~min}$ a day, 5-year-old had $58.0 \pm 16.0$ min, and 6-year-old had 67.6 \pm 19.0 min of activity (Akitake et al. 2016), which was significantly longer than the results of the present study-suggesting that daily MVPA was inadequate under COVID-19.

The preceding studies measured activity time throughout the day, whereas the present study measured only activity in the morning. According to Koizumi (2020), the primary activity time in young children's physical activity over 5.0 METs for over $60 \mathrm{~min}$ a day is between 8:30 and 10:00, free time after lunch, and between 14:00 and 17:00. We conducted measurements for three hours in the morning because the children at the nursery school we surveyed did not have time to exercise in the afternoon because of changing clothes, taking naps, having snacks, and having meetings before going back home.

Children's activity time must have been significantly limited just after childcare at nursery schools was resumed in the COVID-19 pandemic in response to life changes. However, outdoor play at the park had an MVPA more extended than $30 \mathrm{~min}$, significantly longer than indoor play or exercise play. This suggests the need to introduce outdoor play even during the COVID-19 pandemic to secure sufficient exercise time. 
The average heart rate on Monday and Wednesday was significantly higher than Tuesday, suggesting that play associated with exercise more often took place outdoors than indoors, consistent with Tandon's (2015) report that MVPA in children's free play more often appears outdoors than indoors. Moreover, the average heart rate on Monday and Wednesday was significantly higher than Thursday, whereas the activity time was approximately 30 minutes every day, suggesting that the degree of physical activity during outdoor plays was more than indoor exercise plays. On Monday, every class played outside at the park for an equal length of time (the time from leaving to returning to the nursery school was approximately 30 minutes). However, Class B's average heart rate was significantly lower than Class A and C, which might be caused by differences in the type of play, resulting in different exercise intensities. As Kinosita (2017) suggested, young children's play is affected by daily life rhythms at home, changes in parents' schedules of the day, and children's developmental stage and interest.

Exercise play was conducted on Thursday, and the average heart rate of Class A was significantly higher than Class B. Exercise play is an exercise program introduced in childcare for three-year-old or older children, guided by expert instructors. It was the first experience of exercise play for children in Class A, and various types of exercise play were conducted at the orientation. Children in Class B had experienced it in the previous year. However, there was a two-month interval because of the COVID-19 pandemic, and they reviewed the previous year's content. Physical education at preschool facilities and schools is regarded as an opportunity for children to increase physical activity. This study indicated that the degree of physical activity in exercise play was less than outdoor play and that it was less in Class B than Class A. The degree of physical activity in physical education provided at preschools might lead to children becoming smaller, and children's physical strength and athletic ability decline because it takes a long time to listen to instructors' explanations and wait for one's turn. Moreover, a longer time is needed for explanations when the exercise level becomes higher. The level of exercise play in Class B was higher, resulting in less physical activity in Class B.

As described above, the amount of physical activity differed depending on activity content. The time for MVPA, which is expected to improve physical strength, was insufficient. Nursery teachers are forced to change childcare content to prevent infections, and their burden has increased. Therefore, it is necessary to develop childcare programs by considering the degree of physical activity and exercise intensity required to improve children's physical strength, based on children's developmental stage, the climate, and the season.

\section{Limitations}

The survey was only conducted in the morning for five days in June. Moreover, the survey time was limited from the perspective of hygiene, and the number of 
participants was relatively small because children's attendance was not stable due to the COVID-19 pandemic. Furthermore, we did not observe individual plays and could not assess the content of concrete individual activities.

\section{Future Research}

Continuous observations and measurements are required to identify concrete target values for examining childcare in the COVID-19 pandemic.

The Kanagawa Prefectural Sports Center (2009) reported that it is more effective to provide exercise play space for young children focusing on "diversified actions, i.e., quantitative acquisition of movements" and "sophistication of actions, i.e., qualitative acquisition of movements" by increasing the amount of physical activity, rather than improving primary physical strength such as muscular strength and instantaneous force. The free time for exercise play is not correlated with athletic ability, whereas exercise intensity and exercise are highly correlated with athletic ability. It might be more effective to increase physical activity intensity in the available activity time than introduce new programs or spend more time for exercise to improve children's physical activity in childcare settings.

Spontaneous activities and various experiences depending on individual personality and interests are essential in early childhood. However, the types of play (activities) that children perform in a limited time are critical because of the current COVID-19 pandemic. Children's health and development of athletic ability are hindered by insufficient opportunities for physical activities and exercise. It is helpful to offer children exercise play in which children can get absorbed and want to repeat, appropriately supported by nursery teachers. Securing exercise time and increasing exercise intensity should be considered in childcare to increase children's physical activity in childcare.

Further, Children should move their bodies not only in nursery school but also in other settings. Nursery teachers and parents should recognize the importance of physical activity, improve its content, and designate well-defined time for activities. It is essential to share information with childcare and educational settings and local communities and families so that adults around young children can cooperate. The content of future childcare and securing children's opportunities to exercise in the COVID-19 pandemic should be discussed.

\section{Conclusion}

The present study examined the relationship between children's activities at a nursery school and the amount of physical activity in the COVID-19 pandemic and obtained primary data to promote future childcare activities. The results indicated that the content of childcare affected the time and number of children's physical activity. Moreover, the results showed that physical activities with the exercise intensity and time recommended for preschool children are not currently conducted. If the current situation continues, childcare offering exercise 
play absorbs children's attention, and wishes to repeat might have to be practiced. The situation of children in the COVID-19 pandemic revealed in this survey was fed back to the nursery school, and we decided to continue discussions and cooperate in the future. Thus, this study is considered to have a high degree of social contribution and high usefulness in that it is available for improving childcare in the COVID-19 pandemic.

\section{Acknowledgements}

We would like to take this opportunity to express our sincere gratitude to the children and parents of the garden who kindly cooperated with this research, and to the director and teachers who cooperated greatly in the measurement. This work was supported by JSPS KAKENHI Grant Number JP19K14333.

\section{Conflicts of Interest}

The authors declare no conflicts of interest regarding the publication of this paper.

\section{References}

Akitake, H., Tetsuguchi, M., \& Mimura, K. (2016). Relationship between Heart Rate during Endurance Run and Daily Physical Activity in Preschool Children. Journal of Poole Gakuin University, No. 57, 273-285. (In Japanese)

Department of Health and Ageing (2011). National Physical Activity Guidelines for Australians. Physical Activity Recommendations for 0-5 Year Olds. Canberra: Commonwealth of Australia.

Fisher, A., Reilly, J. J., Lelly, L. A., Montgomery, C., Williamson, A., Parton, J. Y. et al. (2005). Fundamental Movement Skills and Habitual Physical Activity in Young Children. Medicine \& Science in Sports \& Exercise, 37, 684-688. https://doi.org/10.1249/01.MSS.0000159138.48107.7D

Kinosita, S. (2017). Study on How Play and Exercise May Affect Early Childhood Development. The faculty journal of Komazawa Women's Junior College, No. 50, 33-42. (In Japanese)

Koizumi, K. (2020). Physical Activity Characteristics and Circadian Rhythm of Body Temperature in Preschool Children who Undergo Physical Activity for more than 60 minutes a Day. Journal of Liberal Arts and Sciences, Chiba University, No. 4, 147-155. (In Japanese)

Ministry of Education, Culture, Sports, Science, and Technology (MEXT) (2012). Early Childhood Exercise Guidelines. (In Japanese)

https://www.mext.go.jp/a_menu/sports/undousisin/1319771.htm

Naito, H., Suzuki, H., \& Sawada, M. (2020). Actual Activity of Infants under the State of Emergency as Seen from the Walking Survey. Juntendo News. (In Japanese) https://www.juntendo.ac.jp/news/20200902-02.html

National Association for Sport and Physical Education (NASPE) (2009). Active Start: A Statement of Physical Activity Guidelines for Children from Birth to Age 5 (2nd ed.). Sewickley, PA: American Alliance for Health, Physical Education, Recreation, and Dance.

Strong, W. B., Marina, R. M., Blimkie, C. R., Daniels, S. R., Dishman, R. K., Gutin, B. et 
al. (2005). Evidence Based Physical Activity for School-Age Youth. Journal of Pediatrics, 146, 732-737. https://doi.org/10.1016/j.jpeds.2005.01.055

Tanaka, C., Ando, T., Hikihara, Y., \& Tanaka, S. (2015). Relationship between Outdoor Playing Time and Moderate-to-Vigorous Physical Activity for Japanese Young Children and Correlates of Physical Activity. Japanese Journal of Physical Fitness and Sports Medicine, 64, 443-451. (In Japanese) https://doi.org/10.7600/jspfsm.64.443

Tandon, P. S., Saelens, B. E., \& Christakis, D. A. (2015). Active Play Opportunities at Childcare. Pediatrics, 135, e1425-e1431. https://doi.org/10.1542/peds.2014-2750

The Kanagawa Prefectural Sports Center (2009). Research on Improving Physical Fitness and Athletic Ability of Children. (In Japanese) https://www.pref.kanagawa.jp/documents/12706/2413_1.pdf

Williams, H. G., Pfeiffer, K. A., O’Neill, J. R., Dowda, M., Mclver, M. L., Brown, W. H. et al. (2008). Motor Skill Performance and Physical Activity in Preschool Children. Obesity, 16, 1421-1426. https://doi.org/10.1038/oby.2008.214

World Health Organization (WHO) (2010). Global Recommendations on Physical Activity for Health.

https://apps.who.int/iris/bitstream/handle/10665/44399/9789241599979_eng.pdf;seque $\underline{\text { nce }=1}$ 